\title{
MANUFACTURING TECHNIQUE AND CONSERVATION TREATMENT OF A UNIQUE GILT-BRONZE STATUETTE EXCAVATED THROUGH RESTORATION OF THE STEP PYRAMID, SAQARA
}

\author{
Gehan MAHMOUD $^{1}$, Ashraf EWAIS ${ }^{2}$, Saleh MOHAMED ${ }^{3, *}$ \\ ${ }^{1}$ Restoration and Conservation Department, Faculty of Archaeology, Luxor University, Egypt \\ ${ }^{2}$ General Director of Saqqara Restoration, Ministry of Tourism and Antiquities, Egypt \\ ${ }^{3}$ Restoration and Conservation Department, Faculty of Archaeology, Fayoum University, Egypt
}

\begin{abstract}
Unexpected excavation of the Osirian statuette was inaugurated in 2021 during a conservation project at the first step in the western façade of King Djoser Pyramid which dates back to the Ptolemaic era. Varies strategies of the examination techniques, such as stereo and polarizing microscopes, and scanning electron microscopy coupled to energy dispersive $X$-ray spectrometry and $X$-ray diffraction were undertaken to characterize the chemical structure of gilt-layer, preparatory layer, and bronze alloy to evaluate their condition. This paper describes the actual condition of the statuette after excavation inside the King Djoser Pyramid, and characterization of the corrosion phases, and determines the best technique for conservation. Visual investigation revealed that the core of the bronze statuette was in good condition, but most gold with gesso was misplaced. Investigation and analyses results demonstrate that amazing technique which gilding has been accomplished as a thin layer over the white substrate from gesso. X-ray diffraction establishes that cuprite and atacamite resulting from the activation corrosion were the major minerals covering the statuette. Besides, calcite and gypsum were detected, which are to be a part of the preparatory layer. EDX results demonstrate that pure gold was likely used in the gilding layer. The gilt-bronze statuette was made of multi-layered surfaces. The solid cast was used in the crafting technique. Fixation of remaining plaster to metal was undertaken using Clucel G(4\%). The figure was immediately treated via popular methods as mechanical tools and solvents. Benzotriazole inhibitor (3\%) was used to cure the activation of bronze disease. The coating system was applied by using 3\% paraloid B72. Finally, the statuette was preserved in the storage with the appropriate conditions.
\end{abstract}

Keywords: step pyramid, gilt bronze, crafting technique, corrosion phase, investigation and analyses, conservation treatment.

\section{Introduction}

An interesting event of gilt bronze statuette excavation inside an open pit in the limestone walls through restoring and maintaining the Djoser pyramid. On the source of the literature, the style of the excavated figure depicts Osiris (god of the dead and giver of eternal life) standing and holding a feather in one hand and a sceptre in the other, wearing a crown with two feathers and two horns. It is consistent with the Osiris representations of Upper Egypt (arms crossed over on the chest) and the other on his stomach pointed out a Lower Egypt style that affirms the possibility [1,2].

The Osirian figure was discovered at the first step inside a small hole between huge stone blocks located in the western façade of the Djoser pyramid, Saqqara necropolis. 


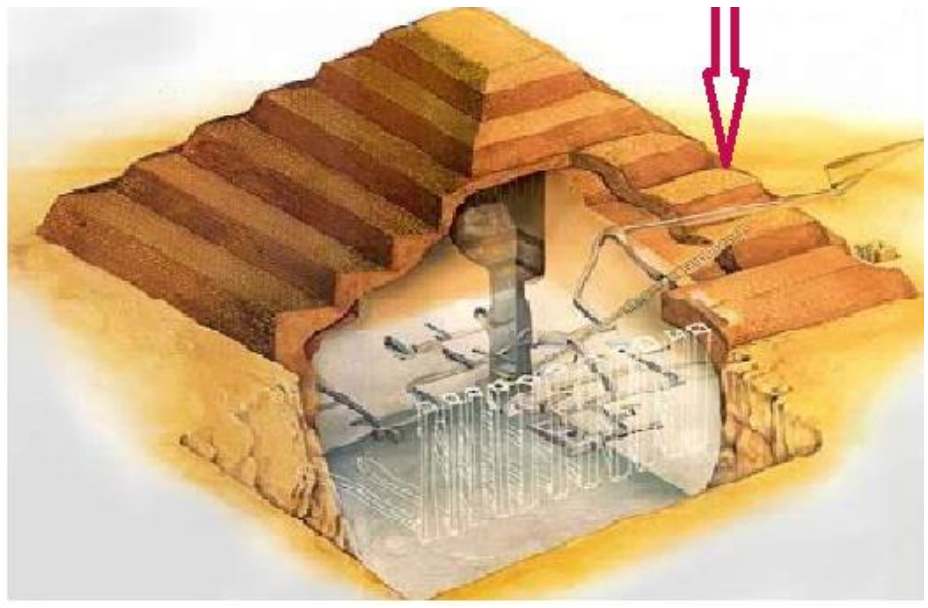

Fig. 1. Schematic of Djoser Step and the excavation site of Osiris statuette [3]

The statuette stands at $63 \mathrm{~cm}$ tall and approximately $15 \mathrm{~cm}$ in width. Archaeologists are puzzled about why the figure was buried inside the pyramid walls. It was likely preserved in that place because Egyptians associated death with the west.

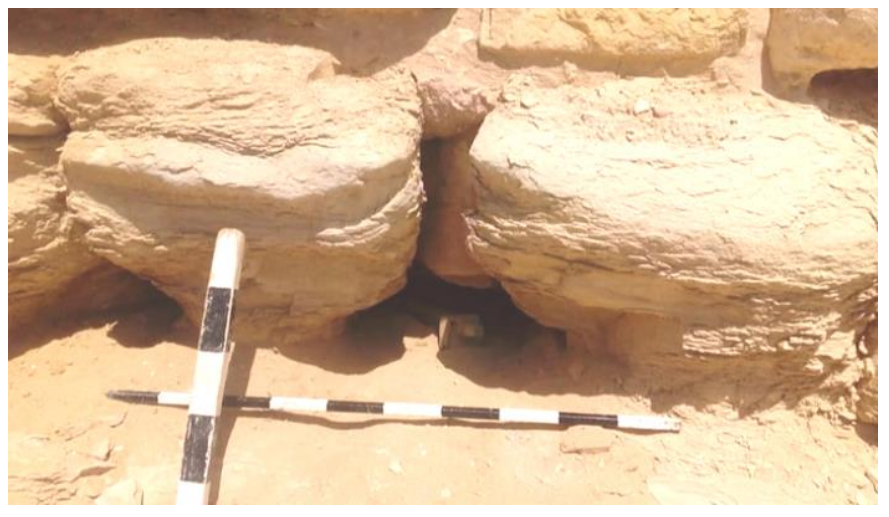

a)

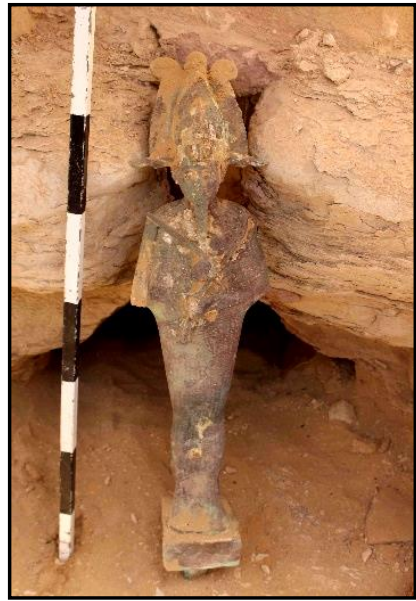

b)

Fig. 2. The actual condition of the Osiris statuette inside the King Djoser pyramid: a) the original environment of the Osiris figure; b) the figure after excavation from its original environment.

Gilding became widespread during the new kingdom (1570-1070 BC) [4]. Osiris figurine object dates back to the Ptolemaic era between the $3^{\text {rd }}$ and the $4^{\text {th }}$ century $\mathrm{BC}$, with a greater probability of originating through to the $26^{\text {th }}$ Dynasty on the basis of stylistic similarities. It wears the white crown of Upper Egypt, the southern portion of the country [5]. In the lower part, the base was likely connected with a wooden part. Previous excavation has revealed an amount of cash of bronze statuettes as well as ritual tools at various sites. The cache of Saqqara and Kharge Oasis are examples of the excavated figures [2]. 


\section{Crafting Process}

The present study takes into account the closest relationship between gilding materials and techniques for conservation purposes. The manufacturing technique is one of the vilest causes of the detachment of the gilding [2].

Gold is soft, yellow, lustrous, the most malleable, ductile, and noble metal; it is very resistant to corrosion. Gold is a rare and costly metal used for gilding the statuette since ancient times. It is often applied as a decorative surface for coating in the form of gold leaves caused by economical and technical reasons as a plated layer in thin leaf [6]; It does not tarnish nor it can not be destroyed. Its first use has been traced back to $3600 \mathrm{BC}$. and was probably obtained in Egypt [7]. Metalworking has long relied exclusively on the understanding of manufacturing scenes from Egyptian tombs.

Over time, these methods have developed to vary the colour, texture, lustre, and durability of gilding and to allow to produce different materials. it was also a process of coating. In early rock carvings as the following illustration in figure (3) from a tomb, Ti at Saqqara of about 2500 B.C. appears gold being beaten with a rounded stone [8].

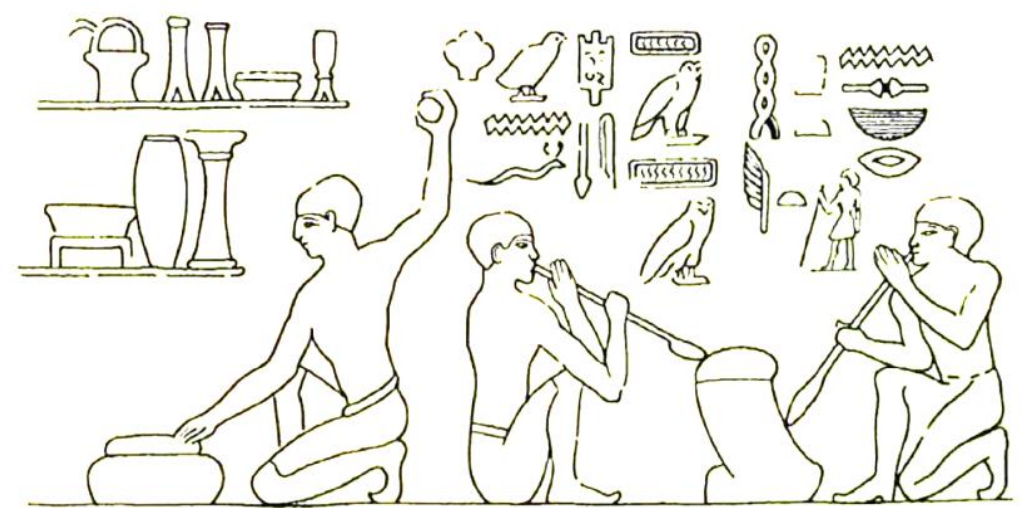

Fig. 3. The most famous illustration from the tomb of $T i$ shows the melting of gold with the blowpipes and the beating of gold with a rounded hammer

Gilding techniques required the knowledge and skill of goldsmith to be produced [6]. Gilding is a performance that includes the application of gold to an equal and hard surface applied in a powder or leaf-like form and in thin layers [9].

Gold foil and leaf have been used by most civilizations to decorate the surfaces. For more than 4000 years, craftsmen have been capable of manufacturing very thin gold foils with a 0.2 $0.3 \mu \mathrm{m}$ thickness. The two techniques were used for obtaining the good quality and colour of the gold film.

Goldsmiths' invention of various kinds of recipes was used to obtain more or less liable adhesion onto those substrates. The minimum thickness of the gilding layer increases intensely with rubbing using mirror polished well-lubricated rolls or using a smooth and hard tool (e.g. agate stone); It was evidently true for the hammering of single foils practised by the artisans [10].

The majority of ancient bronzes have up to $10-30 \%$ tin, as is generally typical in antiquity [2]. Bronze alloys have high corrosion resistance as good as or better than that of pure copper. For this reason, this alloy was used for manufacturing the statuette with gesso. From ancient times until now, the importance and high cost of gilding meant that its use was estimated as a show of wealth by an individual or corporate body designed to impress. For this reason, small bronze statuettes were gilded, specifically in the new kingdom. Gilding was privileged in artworks of religious content or in decorations [11]. 
Out of the set for manufacturing the figure by precision-investment casting, the model was formed by beeswax and then coated in clay hardened when exposed to the high temperature. The wax melted and strained through the holes that were left in the lower part of the clay mould. Then, the molten was poured into the mould through the hole [2].

Gilding with gesso of metals is not successfully practised, but gilding without gesso is most successfully practised [12]. Gold extraction, supplying gold-workers required expeditions to mining sites located in the Eastern Desert [4]. Through the Old Kingdom, the Egyptians exploited gold mines in the eastern deserts. From the Middle Kingdom (about 2025-1700 B.C.), gold deposits of Lower Nubia were exploited. Generally, it was also brought from Syria, Sudan, and the Desert of Libya to the West of the Red Sea on the border of Egypt [13].

Metalsmith used the gilding technique over the preparatory layers to be large and heavy for resistance to the effect of fracture and crash. However, both the crucial role that white preparatory layers give gilding layers more quality and durability [14].

In order to provide the surface to receive the gold leaf, a fine gesso has to be applied to the substrate. This layer was made by mixing chalk or/and gypsum with random sizes. Chalk was likely used to increase the cohesion of the substrate between the ground and the bronze surface. It can control the humid atmosphere [12].

Goldsmith inserted this layer to ease the natural movements of bronze, to create an even and smooth surface [15], and to decrease the friction, which convinced strains on the gold leaves to be suitable for burnishing. Gesso was engraved according to the details and decorations followed by the overlying gold [9], which requested much time and care. Throughout the whole technique, the gilding layer is strained under an in-plane isotropic tensile stress.

Solid casting was normally the most basic technique for manufacturing small statuettes while larger statuettes were produced by the hollow-cast technique to decrease the amount of metal.

Liquid gesso was applied in several layers and, when dry, it was sanded to a smooth finish to create the necessary surface [15].

The form of the base and the heavy mass originate that the statuette was manufactured by solid cast technique. While comparing manufacturing techniques of gilding with gesso and without gesso layer.

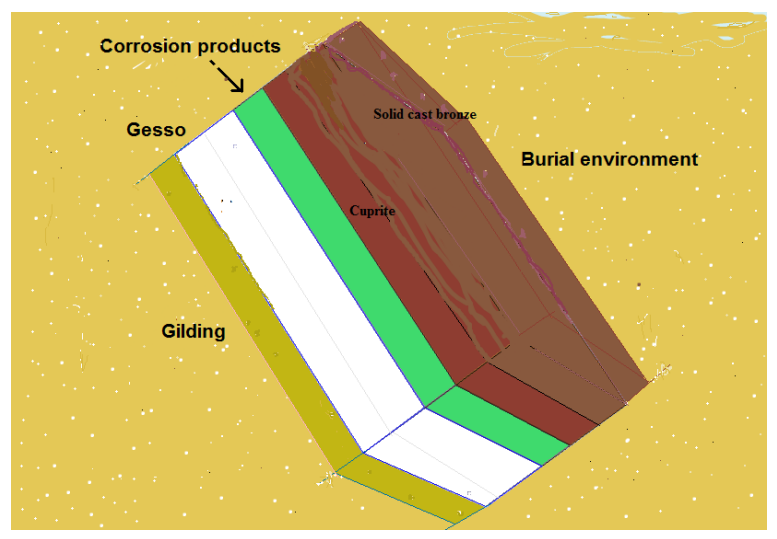

Fig. 4. The layered structure of the gilt-bronze statuette

\section{Degradation of Gilt-Bronze with Preparatory Layer}

These modifications can lead to the activation of corrosion mechanisms that were dormant while burial. Gilt-bronze transforms into corrosion products through the creation period and finally, it gets into stability with the surrounding environment affecting it [16]. Resistance to corrosion of gold and bronze depends on many variables such as chemical structure, element 
properties itself (bronze alloy, preparatory layer and gilt layer), and environment characteristics [17]. There is a relationship between manufacturing technique, chemical structure, corrosion rate, and that time of manufacture is related in certain cases, which allow dating [18].

Corrosion rate rests on normal exhausting processes before burial as well as on all chemical and physical changes of the burial environment. In suitable climatic conditions like inside the Step pyramid walls, the green surface layer is formed in a long period; because of a salty environment where the corrosive ions of chloride and sulphide, as well as carbon dioxide, oxygen, and relative humidity, are regarded as the most active agents for corrosion the statuette [2].

Sharply demarcated stains and stripes are dark-red or turning green or blue formed on the bronze surface, especially at places where humidity and pollutants are held up and dried out. This consequence is enhanced even by the presence of mild hygroscopic deposits [16].

Post-corrosion of the gilt-bronze statuette after excavation, it does not look like in the surface morphology of non-gilt bronze. The gilding layer is covered by green patina mixed with soil salts and sometimes is even trapped inside them. The gold leaf shows a great continuity, when dragged by corrosion products and tends to deform before breaking [19].

The preparatory layer as the substrate of the gilding layer has positive and negative aspects. The positive aspect, it decreases galvanic corrosion. The negative aspect, it is a porous material increasing the corrosion rate of the bronze alloy by adsorbing the humidity. Where gilding has been applied to gesso, it can also be a problem when decay occurs in this layer. There is a relationship between the gesso and gilding layer; missing parts of the plaster are related to the gilding layer. The preparatory layer was not completely bonded in some parts.

Chloride ions present in the burial environments are affected aggressively, which can cause extensive corrosion and detach the gilding layer. Acidic and salt-rich sediments would also favour the corrosion of metals. While low $\mathrm{pH}$ values normally cause thermodynamic instability of the outer corrosion layers (oxides and hydroxides), high salt and clay mineral contents would provide highly conductive electrolytes [20].

Gilt-bronze statuettes are often concreted with green corrosion products through the burial environment due to the poor condition of the surroundings. Only there may be deformation of the gold object because of softness [21].

Indeed, chemical reactions and physical phenomena induce the formation of a nearly composite structure including metallic relics, soil constituents, mineralized metallic insoluble phases, and products formed from the interaction between soil components and metal corrosion compounds. In some cases, these products pseudomorphically replace the previously existing metallic matrix and in other cases, entirely new structures are formed. Serious decay of the gilding layer occurred on the statuette as tarnishing, stress corrosion cracking, and embrittlement caused by the homogenous chemical structure of the gilt bronze. The thin film of the gilding layer can either be derived from the deposition of metallic ions from solution (such as iron staining) or reactions with sculpture-containing contaminations, particularly hydrogen sulphide. It is also well known that tin is selectively dissolved from the alloy into the outer medium, which is referred to as destanification or tin de-alloying [22, 23]. Gilding was frequently finished by an exhausted gold leaf, which removed a thin and porous layer to be smooth. The presence of these depletiongilded layers over debased gold alloy often produces severe corrosion [16]. The purpose of this paper is to provide an overview and comprehensive study of the casting technique of the gilt bronze statuette, its condition and chemical structure, and conservation procedures.

\section{Materials and Methods}

Archaeological materials specialized in the components of the gilt-statuette, gold, gesso, and bronze alloy are heterogeneous materials that give non-reproducible results. For this reason, the results were crossed with numerous investigations and analyses. 


\section{Sampling}

Three methods were used to prepare samples; mounting in resin, drilling, and solid. Loosely adhering samples, and fragments were taken from the preparatory layer, corrosion products, and soil sediments. The cross-sections of bronze patina obtained from separated corroded areas were embedded in Araldite resin. Then, they were crushed via 400-1200 grit for polishing after the necessary curing time to smooth.

Thin-section was prepared by heat-affected to place on the glass slide for investigation of the substrate composed of soil sediments mixed with corrosion products.

The polished surface of the sample was examined under reflected light using a polarizing microscope. Powder samples from the interface of bronze/gesso were submitted to X-ray diffraction. It was so difficult to take a sample from the bronze core; it was not allowed to scratch the figure.

\section{Investigation Microscopy}

The qualitative investigation and analysis were undertaken to identify the chemical structure of gesso, the corrosion products, and soil sediments. The main purpose was monitoring the degradation features of the figure induced by the burial environment, as well as the response of the coating under different environments.

\section{Stereomicroscope}

Leica S9i, Stereozoom microscope was used for the structure investigation of gilt surface and corrosion products, (50x-500x magnification), with both visible and fluorescent light, and a digital video camera system. It was used to characterize the properties of coloured corrosion products and their differences as non-uniform green patina caused by the reaction of copper with environmental pollutants like chlorides.

\section{Polarizing Microscope}

Leica DM500 polarizing microscope was used in investigating the original surface of the statuette. This microscope is a very efficient tool for the identification of soil sediments overlapping with corrosion products.

\section{Scanning Electron Microscopy Equipped with Energy-Dispersive X-Ray}

Scanning electron microscopy equipped with energy-dispersive X-ray microanalysis (SEM-EDS) was made by Quanta FEG microscope used for the investigation and elemental analysis of the deterioration phenomena. SEM and EDS results of the samples were attained by using a JSM-6380 LA instrument, equipped with a Link EDS operating up to $30 \mathrm{kV}$.

\section{X-Ray Diffraction}

Powder samples from the interface of bronze/gesso were submitted to X-ray diffraction. X-ray diffractometer model Philips PW1840 was used for the identification of the chemical microstructural of gold leaf and corrosion products using $\mathrm{CuK \alpha}$ radiation source. Characterizations of crystalline phases were performed using the database PDF2. X-ray diffraction was undertaken to ensure the characterization of the composition of the preparatory layer with corrosion products in the interface.

\section{Results}

Visual examination revealed that most substrate layers of the gesso and gilding layer were detached from the bronze surface caused by corrosion activation and deterioration of substrate materials. Some parts, corrosion products and soil sediments are more compact, without evidence of porous or micro cracks. 


\section{Stereomicroscope Results}

General view of the morphology of the surface, displays a stratigraphic structure of layers typical. Topological features of the gilding layers were investigated by a stereomicroscope.
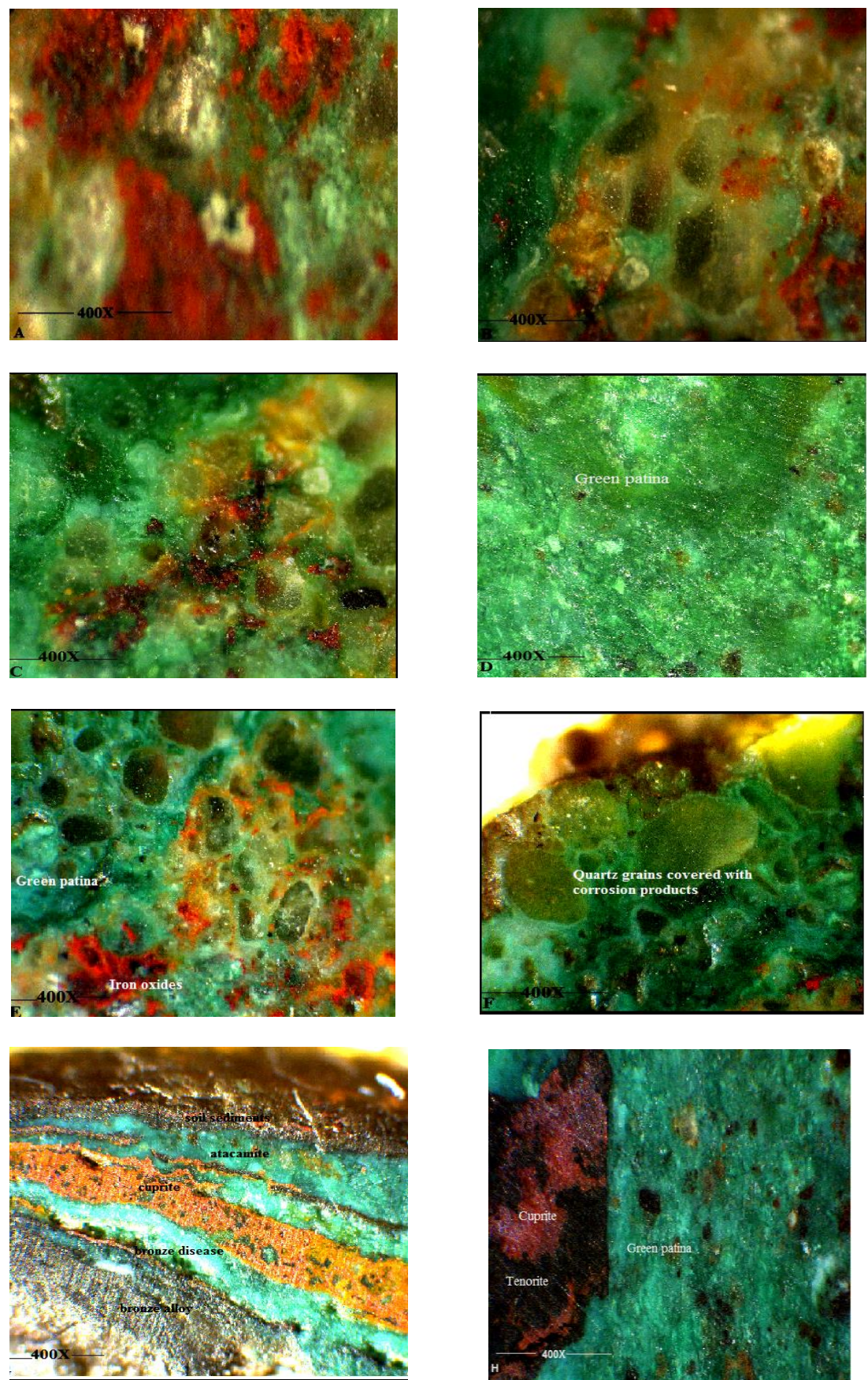

Fig. 5. Stereomicroscope of the interface of the corrosion products/gesso shows the surface condition and the morphology of bronze-green patina 
In Fig. 5, A and B show the formed-copper corrosion products with iron rust stains on the surface. $\mathrm{C}$ shows the holes in the oxide layer filled with cuprite. $\mathrm{D}$ appears the green patina covered uniformly over the surface in the stability parts. E shows the distribution of iron oxides on the substrate (bronze/gesso). F shows corrosion products concreted with environmental sediments. G appears cross-sections of layered corrosion in an active corroded area (cuprite and green patina covering the metal core). $\mathrm{G}$ and $\mathrm{H}$ show a cross-section of bronze patina in green colour followed by primary patina in red-brown colour (with minor contributions from the mounting resin in the $\mathrm{G}$ ). The volume of the patina increased at higher concentrations in the activated corrosion area, at the same time decreasing adhesion to the bronze surfaces, and deteriorating the look of the patina. Tenorite is the result of cuprite oxidation in an arid environment or under heating conditions, and it is thus rarely found in corrosion layers of bronze artefacts but is likely produced on heating [1].

\section{Petrography Microscope}

The deposition of the environmental and corrosion products on the gilt layer and the preparatory layer were investigated. The abnormal growth of soil grains with corrosion products on the bronze surface is shown in Fig. 6. The same field of view in figures A, B, C, and D shows sand and clay minerals admixture with green patina. They frequently occur through the burial environment.
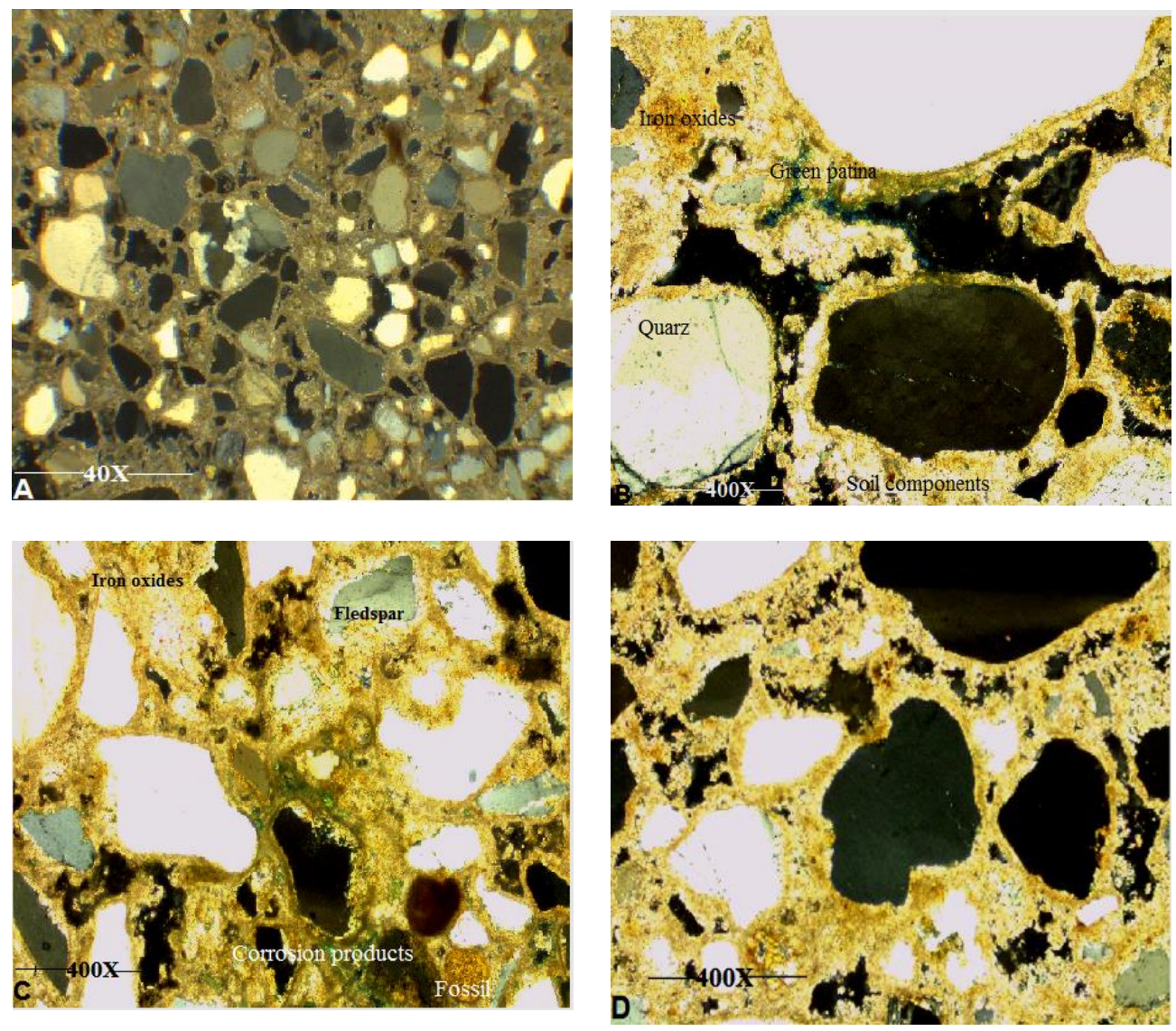

Fig. 6. Thin section images of soil and corrosion products 


\section{SEM/EDS Results}

Scanning electron microscopy was carried out on gesso with gilding layer for revealing fine morphology as shown in Fig. 8. Back-scattered imaging does provide a visual of the microstructure of the variety of soil deposits seen at the macro scale. White and Gray scare are influenced by the atomic weight of the gold and the preparatory layer. SEM results revealed the gold remains and gypsum in white, soil products in light-grey, and gesso in blackish-grey.

Sample (A and B), SEM-EDS shows that carbon, oxygen, and calcium were detected in high percentage referring to calcite as the major mineral in the gesso layer. Silicon was detected in high percentage as well as iron, aluminium, and chlorides caused by the effect of the burial environment. At the same time, sulfur was not detected, indicating that gypsum was minor in this area were detected in a high percentage caused by the effect of burial materials. Gold recorded a high percentage resulting from the coherent with the preparatory layer. Zinc likely indicated the presence of white components in the preparatory layer.

Sample (C and D), SEM-EDS shows the high amounts of ( $\mathrm{Ca}$ and $\mathrm{S}$ ) referring gypsum and calcite are the main components of the preparatory layer. Results enhance strong correspondences between the burial environment and separated samples from the statuette.

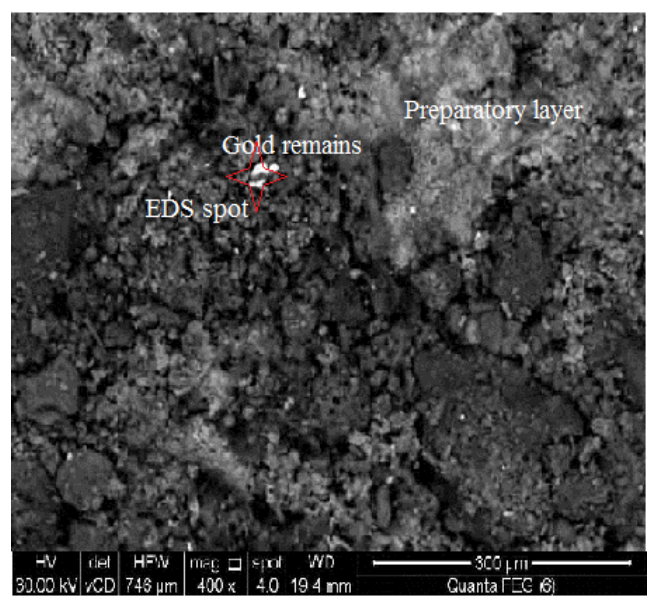

a)

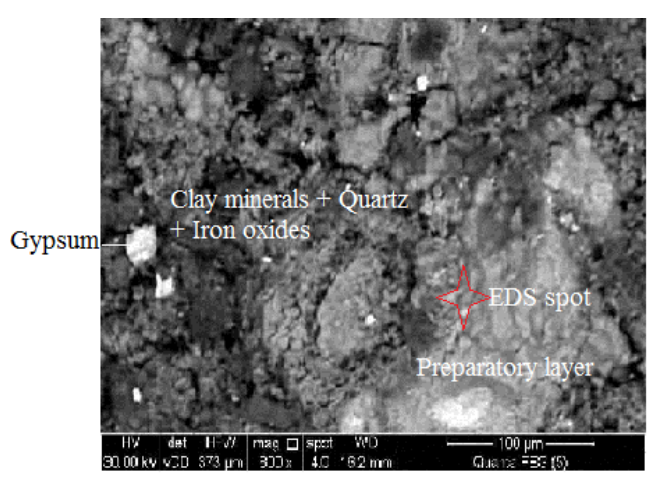

c)

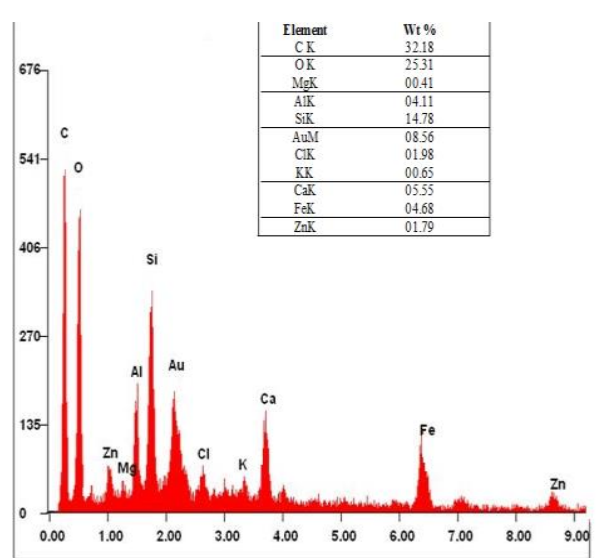

b)

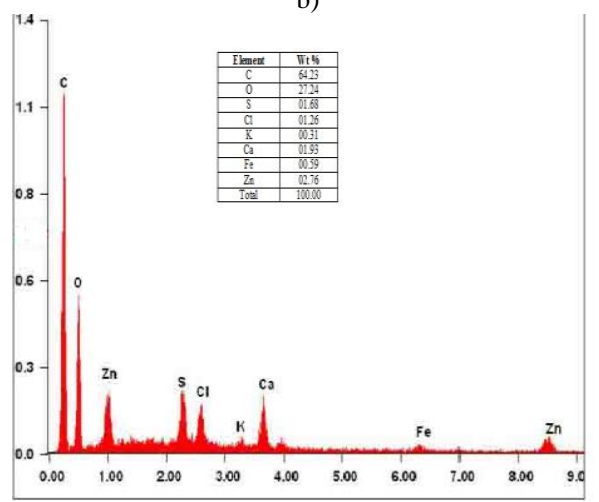

d)

Fig. 7. SEM-EDS result of gesso with gilding layer and soil deposits: a) and b) SEM-EDS shows the deformation of gesso with gold remains; c) and d) SEM-EDS shows the alterations of the preparatory layer. 


\section{X-RAY Diffraction Analysis (XRD)}

The identification of gesso with gilding and bronze patina on the figure is a basic goal in order to assess their conditions and to determine the conservation procedures.
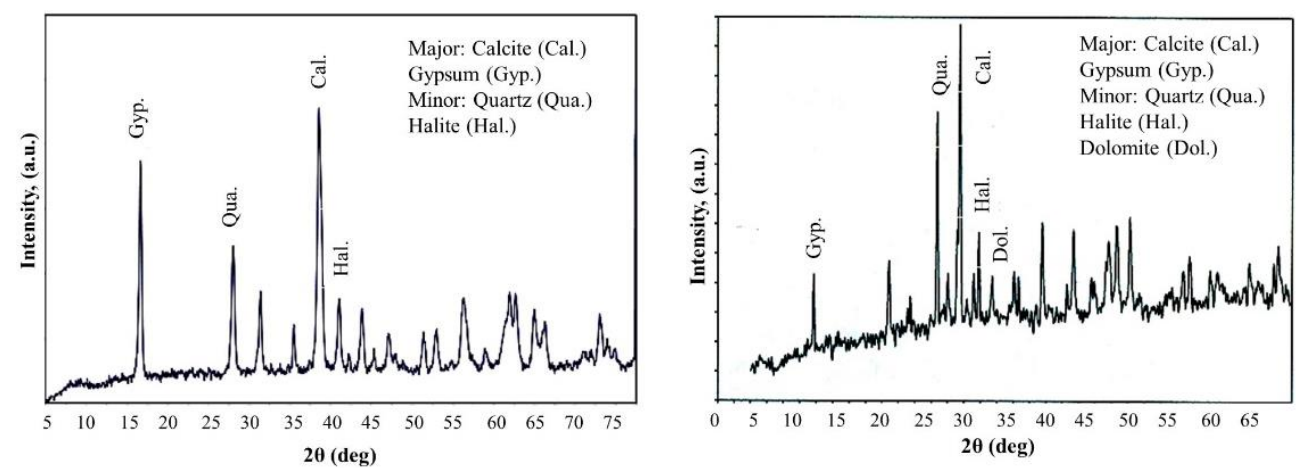

a)

b)

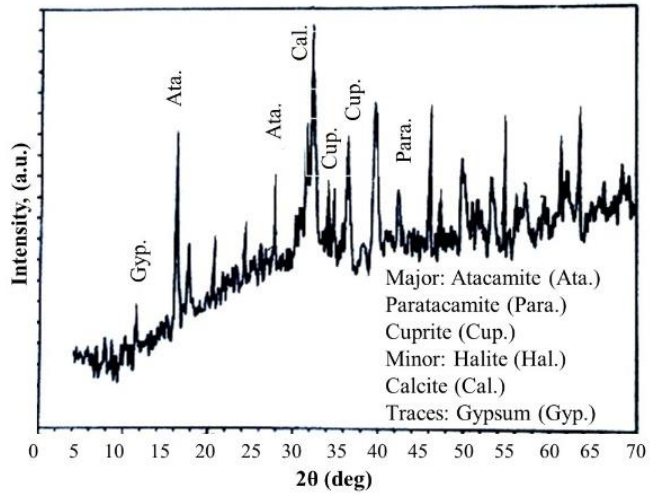

c)

Fig. 8. XRD pattern of corrosion products and the substrate gesso traces of soil sediments: a) XRD pattern shows the presence of gypsum and calcite originates from the preparatory layer; b) XRD pattern shows that calcite and quartz are the major products; c) XRD pattern shows that active corrosion area composed of atacamite, paratacamite, and cuprite.

$\mathrm{X}$-ray diffraction results revealed that calcite is the major in the white preparatory as well as gypsum. They represent the main minerals of this layer with quartz. Atacamite and paratacamite were detected in the active corrode area. The decrease observed in gypsum was revealed in the preparatory layer.

\section{Condition of the Osiris Statuette}

Parallel to the reported results of investigation and analyses of the gilt statuette, alloying elements, and white preparatory were performed. It was only partially buried in the salty sand environment of the excavated site; it was the reason for the creation of the surface morphology. Bronze patina is usually obscured by dark-red brown representing a self-protective surface composed of cuprite. Cuprite with vitreous green deposits has been seen caused by cyclic oxidation. Copper deposits changed the surface colour into green in the activated corroded area. Remains of a gilt surface with a gesso layer were fragile, partially deformed, and displaced from their original positions. 
The corrosive forms and cavities of bronze disease on the substrate resulting in bronze destruction have a relation with chemical corrosion reaction. The continuous oxidation of cuprite causes an expansion of the volume with growths of copper oxides and corrosion products, which displaces and fractures the white preparatory with gilding. Although the statuette did not hold under pressure from soil layers or mass rocks, the gilding layer was deformed by dragging corrosion products.

The surface morphology and compactness of the gilded layer were confirmed that gesso was separated from the bronze alloy in the active corroded area. Once the gilding layer is broken, the porosity of the gesso and the presence of hygroscopic products such as chloride compounds underneath this layer tend to be delicate and accentuate the corrosion process to avoid gilding completely.

The gilding layer was worn out in some places thus creating oxygen-permeable zones and starting corrosion. Besides, adsorbed humid formed in the substrate engaged as the electrolyte film, which activates the corrosion phases. Gesso surface appeared dry, but dampness on the porous was observed over the bronze alloy; because it has a very high storage capacity for water. When the white preparatory was dissolved, gold/bronze creates galvanic cells, which increase galvanic corrosion.

A careful examination of the surface reveals loose gilding in the straight places and overlaid on their edges. No crevices or deep pits were detected on the bronze surfaces. Statuette Surface was covered with crusts of sand, dust, and salts.
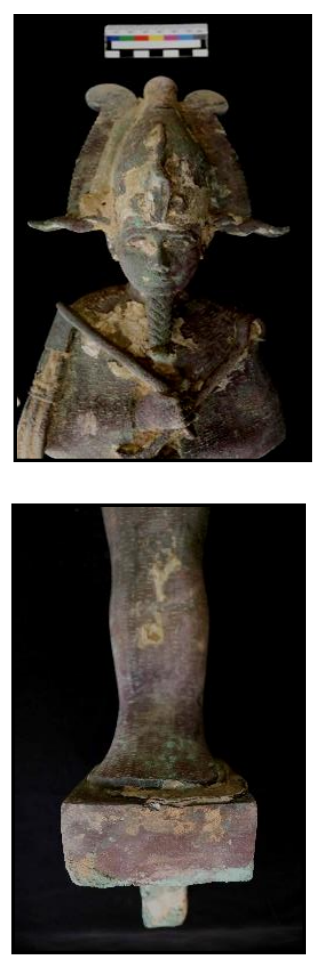
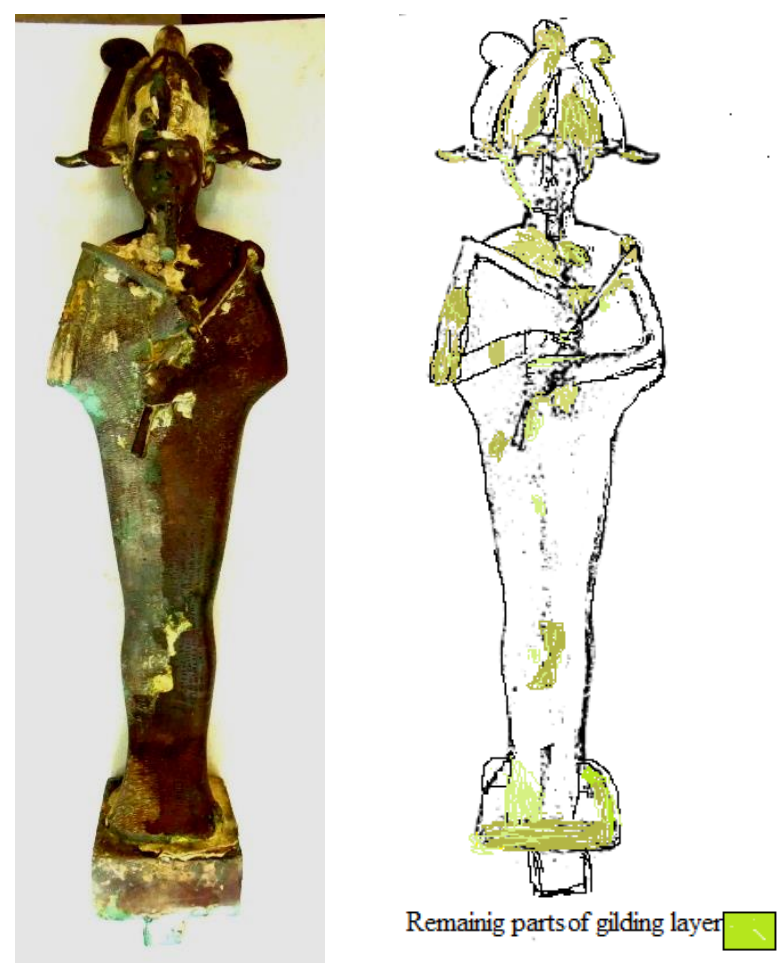

Fig. 9. Model of the statuette and the appearance of parts loosen in the gilt surface

Generality, most of the body was covered with noble bronze patina in red-brown colour protecting the core of the alloy. 


\section{In Situ Conservation Procedures}

The protection of this rare heritage is the long-objective term in life. Although the gilt statuette was excavated in good condition, conservation of gilt-metal artefacts required challenge; gilding is a sensitive and delicate practice. It was composed of several layers, and maintenance was more complex; each one needed a different technique. Conservation treatments varied according to the surface morphology of white preparatory and corrosion products found, it was accomplished with professional ethics with paying extra attention.

Fixing the gilding layer was the first step in the conservation of the statuette. Correspondingly, the quick fix of gesso providing was outweighed many times compacted with a bronze surface by removing them or the loss of the gilding [11].

Restorers/Conservators face many difficulties when a gilded statuette is submitted to mechanical cleaning via hand-operated mechanical tools to remove corrosion and soil crusts in order to recover the original appearance. Brushing provides the only safe method to be employed in the preservation of the gilt layer. Brushes and scalpels were used for the removal of visually incoherent corrosion deposits and burial encrustations. Also, cleaning the surface with solvents was used to remove the stains; it did not cause etching of remains gilding layer and bronze patina but they brightened up.
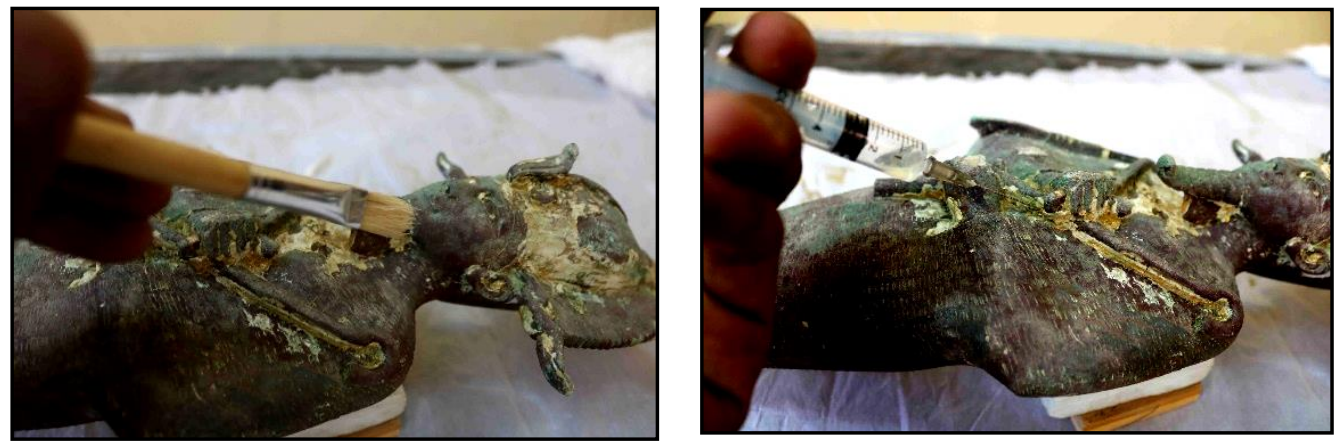

Fig. 10. Treatment of figure and reassemble of the gesso remains
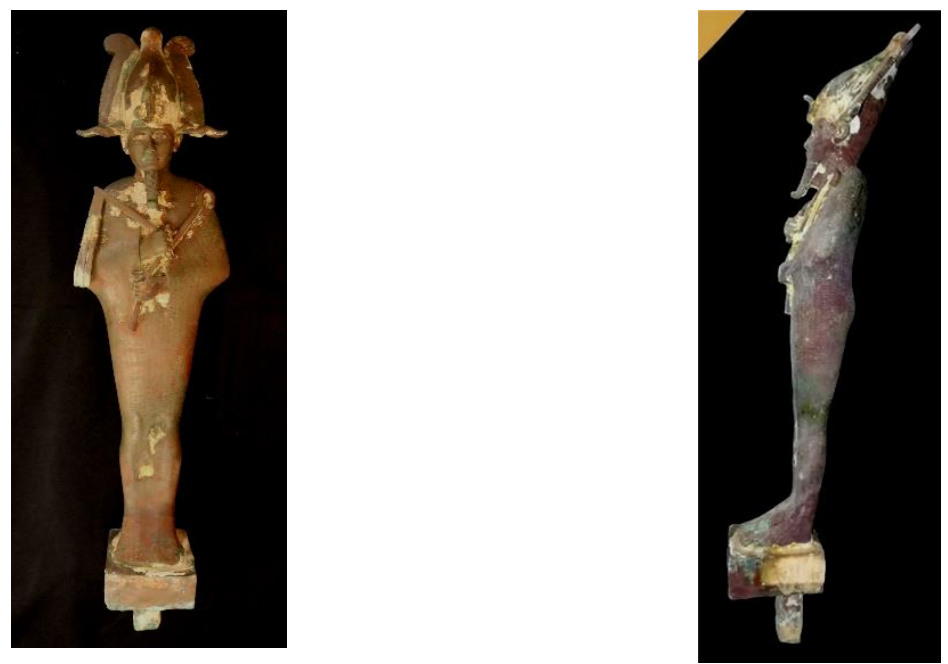

Fig. 11. Osiris figure after finishing the treatment, reconstruction of white preparatory, and coating of the bronze surface 
Chemical cleaning by using a mixture of toluene, ethanol was undertaken for removing soil deposits. Reassembling broken filling losses on the remains of the white preparatory was performed by using Clucel G 4\%, as an overall consolidant type. Post excavation stability of the activated corroded areas was undertaken by desalination treatment using $3 \%$ benzotriazole. Then, Paraloid B-72 was used as the protective coating of the gilding statuette.

Great preservation was performed for this object-at polyethylene bags after wrapping inside water-based polyurethane to coat or seal surfaces. The application of preventative conservation is most important for protecting this heritage for the long term. Continuous checks of chloride ions should be undertaken to forbid the eventual structural failure as well as the protective coatings. It should be safeguarded simply by keeping it dry, out of harm's way to conserve the value of the gilded artefacts [11].

\section{Discussion}

Osiris figure was found during conservation works at the step pyramid. Gesso (gypsum and calcite) was added as a substrate in viscous solution to represent a specific layer between gilding and bronze alloy. That relatively thick gold leaf was not applied directly on the bronze body, but an intermediate thick layer of preparatory layer, a mixture of quartz, calcite, and an organic binder lie in between the alloyed structure surface and the gilding film. That gesso layer is itself engraved with decorations followed by the overlaying gold [11].

There was no homogeneity and facilitate uniform distribution of gypsum with calcium carbonate. EDS revealed that sulphur was not detected in the samples of the preparatory layer. Corrosion spreads on the surface, instantly under the preparatory layer, producing noble bronze patina (cuprite). For these reasons, most gilding layer is detached, especially in the flat area with the exception of some details in the upper half.

Investigation and analytical results demonstrate the compositional and technologic data of the gilt-bronze statuette. Through the burial condition of the gilt-statuette exposed to greater wear and less protected environment affected on its surface.

The cross-sections and bronze patina, obtained from fragments embedded in Araldite resin and polished after the necessary curing time. Based on the presented information from the stereomicroscope, the green patina-covered bronze alloy was not a straightforward substrate. Bronze alloys are composed of copper and tin, which are the most common metals. Gesso and gilding layers played as a coating of the bronze surface in the dehydrated conditions. Until the figure was buried, gilt-bronze tried in balance with the adjacent deposits; it was well-preserved. Although the bronze disease was detected on the interface, pits are almost invisible.

In the burial environment, saturated sodium chloride attacked gold and copper. Also, corrosive mechanisms were activated when the object was excavated from its original environment because of the different hygrometric situations. Soil deposits reinforced with green corrosion crusts covered all the statuette surfaces [21].

The tin oxide is stable in dehydrated conditions, it is cathodic in the electrochemical cell with comparison to the copper. The copper ions formed during the corrosion may produce a layer of patina on the surface, whereas tin products continue in the interior of the corrosion layer [24].

Those salts penetrated to the bronze core through the pores and cracks producing bronze disease [16]. Remains of gilded areas were rather protected from the effect of salts.

In some cases, objects seriously affected by the environmental pollutants tended to the gilding trapped on the surface as small parts. Loss of the gilding layer occurs rapidly when the plaster layer could allow high moisture to penetrate inside the body of the statue causing corrosion of bronze alloy. Detaching and flaking the preparatory layer with the gilding layer of the statuette appeared corrosion products, which was closely intermixed with the bronze surface. Furthermore, XRD results enhance strong correspondences between the burial environment and separated samples from the statuette surface. 
Based on by XRD and EDX results, all the identified corrosion products confirmed that active dissolution of the bronze core involves the determination of chloride-rich products such as atacamite and paratacamite which have been engaged from the soil salts as halite.

X-ray diffraction results determined the extent of corrosion products mixed with soil deposits. The preparatory layer identified in most samples were made of calcite and the presence of gypsum. At the same time, these results point out that the relatively higher calcite than preparatory layer. Chloride products present in most of the analyzed samples were very aggressive agents which cause a high rate of corrosion.

$\mathrm{XRD}$ results confirmed with indication copper (II) salts as atacamite $\mathrm{CuCl}_{2} \cdot 3 \mathrm{Cu}(\mathrm{OH})_{2}$. EDS results revealed that the thin leaf is generally denoted by alloys of Au. Despite the zinc detection by EDS elemental analysis in the gesso, no matched elements were found in the XRD.

Gilded remains can be removed mechanically resulting from scratches or fractures by scalpels as well as swelling the preparatory layer through the chemical treatment. The gold film is exactly a thin leaf; conservators faced many problems through the conservation of Osiris's figure. Conservation treatment was performed carefully via soft brushes without scratches. Accumulates in the grooves with porous areas, where the gold layer was not compacted by burnishing. Fixing the gilding layer with plaster was performed by Clucel G 4\%. Spraying solvent was the appropriate technique for consolidating the preparatory layer through the fixed area. Removal of chloride ions from the corroded crusts underneath gold leaf was performed by $3 \%$ benzotriazole.

\section{Conclusions}

The Osiris statuette was likely discovered alone came from ancient preservation. This figure was made from ternary alloy $(\mathrm{Cu}-\mathrm{Sn}-\mathrm{Pb})$. Bronze core followed by preparatory layer admixed with gilding layer composed of the gilt statuette. The determination of the chemical composition of gesso was undertaken by preparatory layer which was made of calcite admixed with a low percentage of gypsum.

The discovered statuette was in good condition; because it was preserved in dry conditions inside the Djoser pyramid's wall, although detection of the active corrosion areas. Corrosion products extended on the surface, instantly under the preparatory layer, producing bronze patina in different colours. For these reasons, most gilding layers are detached, especially in the flat and embossed areas except for some details in the upper half.

The surface of the statuette was covered by red and greenish cuprite and atacamite. Increasing the thickness of bronze patina in the active corroded areas was the reason for detaching the gilding layer the activation of the corrosion mechanism was covered with green patina. Also, the unusual nature of the gilding layer was detached with preparatory layer remains.

The adhesion mechanism between gold leaf and its substrate was decreased with the effect of humidity and corrosion products. XRD results demonstrate that green patina is composed of atacamite and paratacamite. The preparatory layer is composed of gypsum and calcite. SEM/EDS results confirm that gypsum and calcite were used in manufacturing the ground of the gilt layer.

Corrosion products were removed mechanically and the surface was fixed and consolidated with Clucel G 4\%. Activated corrosion areas were stabilized by $3 \%$ benzotriazole. Then, Paraloid B-72 was used as the protective coating of the figure.

\section{References}

[1] Agresti, J., Osticioli, I., Guidotti, M., Capriotti, G., Kardjilov, N., Scherilloe, A., and Sianoa, S., Combined Neutron and Laser Techniques for Technological and Compositional Investigations of Hollow Bronze Figurines, Journal of Analytical Atomic Spectrometry, 2015, 30, pp. 713-720. 
[2] Ghoniem, M., The Characterization of A Corroded Egyptian Bronze Statue And A Study of The Degradation Phenomena, International Journal of Conservation Science, 2011, 2(2), pp. 95-108.

[3] Dunn, J., The Step Pyramid of Djoser at Saqqara in Egypt Part III: The Primary Pyramid Structure, http://www.touregypt.net/featurestories/dsteppyramid1.htm

[4] Plenderlieth, H. J., and Werner, A., The conservation of Antiquities and Works of Art, Treatment, Repair and Restoration, $2^{\text {th }}$ Edition, Oxford University Press, London, 1971.

[5] Scott, D., and Dodd, L., Examination, Conservation and Analysis of a Gilded Egyptian Bronze Osiris, Journal of Cultural Heritage, 2002, 3, pp. 333-345.

[6] Mazé, C., García, J., Quirke, S., and Stauder, A., Precious Things, The social Construction of Value in Egyptian Society, From production of Objects to their Use (mid $3^{\text {rd }}-\operatorname{mid} 2^{\text {nd }}$ millennium BC), in "The Arts of Making of Ancient Egypt, Edr., Miniaci, G., p. 115.

[7] Rose, A., and Cirino, A., Jewelry Making And Design An Illustrated Text Book for Teachers, Students of Design, and Craft Workers in Jewelry, Metal Crafts Publishing Co. Providence, R. I., 1917.

[8] Cardoso, I., and Pye, E., Gessoes in Portuguese Baroque Gilding Grounds. Part 2: Analytical Study of Historical Samples and Archaeological Reconstructions, Studies in Conservation, 2017, 62(4), pp. 1-25.

[9] https://colonialrestorationstudio.com/gilding-gold-leaf.html

[10] Darque-CerettiI, E., FelderI, E., Aucouturier II, M., Foil and Leaf Gilding on Cultural Artifacts; Forming and Adhesion, Revista Matéria, 2011, 16(1), pp. 540 -559.

[11] Howell, K., Gilding, https://www.buildingconservation.com/articles/gilding/gilding.htm

[12] Maspero, S., and Oxon, D., Manual of Egyptian Archeology and Guide to Study of Antiquities in Egypt for The Use of Students and Travelers, Publisher: Cambridge University Press, 2012, ISBN:9780511716461, doi: 10.1017/CBO9780511716461

[13] Sandu, I., Afonso, L., Murta, E., and Desa, M., Gilding Techniques in Religious Art Between East and West, 14-18 ${ }^{\text {th }}$ Centuries, International Journal of Conservation Science, 2010, 1(1), p. 47.

[14] Cardoso, I., and Pye, E., Gessoes in Portuguese Baroque Gilding Grounds. Part 1: Analytical Study of Historical Samples and Archaeological Reconstructions, Studies in Conservation, 2017, 63(2), pp. 1-25.

[15] Jenkins, M., Gilding Technique, Care and Maintaince, Technical Conservation, Research and Education Group, Historic Scotland, Edinburgh, 2007.

[16] Knotkova, D., and Kreislova, K., Atmospheric Corrosion and Conservation Of Copper And Bronze, State of the Art in Science and Engineering, 2007, 28, p. 109.

[17] Shifler, D., Understanding Material Interactions In Marine Environments To Promote Extended Structural Life, Corrosion Science, 2005, 47, pp. 2335-2352.

[18] Weisser,T., A Perspective on The History of The Conservation of Archaeological Copper Alloys in The United States, Journal American Institute for Conservation, 1994, 33(2), pp. $141-152$.

[19] Barrio, J., Chamon, J., Ferretti, M., Arroyo, M., Pardo, A., Climent, A., Ynsa, M., and Gultierrez, P., Study of Conservation Problems of the Archaeological Gilded Metals from the Islamic Site of Qalat Rahab, Proceedings of Metal, 2004, National Museum of Australia Canberra ACT, ABN 70592297967.

[20] Reale, R., Plattner, S., Guida, G., Sammartino, M., Visco, G., Ancient coins: cluster analysis applied to find a correlation between corrosion process and burial soil characteristics, Chemistry Central Journal, 2012, p. 2. 
[21] Janposri, K., Conservation of Metal Objects in Thailand, Conservation of Metals in Humid Climate, Proceedings of the Asian Regional Seminar, ICCROM, 1987, p.53.

[22] Deck, C., Care and Preservation of Historical Brass and Bronze, Benson Ford Research Center, 2020, www.thehenryford.orgs

[23] Scott, D., Metallography and Microstructure of Ancient and Historic Metals, Metallography and Microstructure of Ancient and Historic Metals, Marina del Rey, CA: Getty Conservation Institute in association with Archetype Books, 1971, p.44.

[24] Robbiola, L., Fiaud, C., Pennec, C., New Model of Outdoor Bronze Corrosion and Its Implications for Conservation, Archives-Ouvertes Fr., 2014, p.798.

Received: November 06, 2021

Accepted: December 12, 2021 